\title{
Miguel Miguel: a dobra do nome
}

Miguel Miguel: the name doublés

\author{
Luís Heleno Montoril del CASTILO* \\ Universidade Federal do Pará (UFPA) \\ Stélio Rafael Azevedo de JESUS ${ }^{* *}$ \\ Universidade Federal do Pará (UFPA)
}

RESUMO: O presente artigo tem por objetivo analisar e interpretar a novela Miguel Miguel, de Haroldo Maranhão e a relação da dobra do nome Miguel como uma questão de linguagem literária. A literatura tem o privilégio de não estar presa às regras da verdade histórica, pois a imaginação opera como elemento essencial que subverte a lógica exigida pelo real e instaura a ambiguidade. Assim, pode-se inferir que o duplo se articula com a palavra para recriar no mundo do texto o espelho que reflete a diferença, abstraída da repetição do nome. Nessa perspectiva, filosofia e literatura se entrecruzam para pensar a narrativa complexa de Haroldo Maranhão.

PALAVRAS-CHAVE: Miguel. Duplo. Linguagem. Haroldo Maranhão.

ABSTRACT: This article has by objective to analysis and interpret the novel Miguel Miguel, by Haroldo Maranhão and the relationship of the fold of the name Miguel as a matter of literary language. Literature has the privilege of not being bound by the rules of historical truth, for imagination operates as an essential element that subverts the logic required by the real and establishes ambiguity. Thus, it can be inferred that the double articulates with the word to recreate in the text world the mirror that reflects the difference, abstracted from the repetition of the name.

\footnotetext{
* Doutor pela UFMG, com pós-doutorado em Literatura Comparada: CAPES / Sorbonne Nouvelle-Paris 3. Professor de literatura no Programa de Pós-graduação em Letras (PPGL/UFPA). E-mail: lenomontoril@gmail.com

** Mestre em Estudos Literários pelo Programa de Pós-graduação em Letras (PPGL/UFPA). E-mail: rafa_azevedo17@hotmail.com
} 
From this perspective, philosophy and literature intersect to think of Haroldo Maranhão's complex narrative.

KEYWORDS: Miguel. Double. Language. Haroldo Maranhão.

\section{Introdução}

O inevitável estranhamento é recorrente em Miguel Miguel (1993). O espelhamento do eu é o reflexo da duplicação operada na linguagem, cujo jogo narrativo evoca ambiguidades e convoca ao retorno às primeiras páginas da obra. Essa dinâmica surge já no início da curiosa novela, quando o narrador Varão, amigo e colega de trabalho de Miguel, tem o hábito de, ao abrir o jornal, consultar primeiro o obituário. Em um dos obituários, um suposto general M, expondo-se à morte ante um campo de batalha, acaba falecendo de uma simples gripe. Certo dia, para sua surpresa, depara-se com o nome do amigo, que sempre o visitava para a macarronada aos domingos, ao lado da esposa e dos dois filhos gêmeos. A notícia da morte espanta Varão: "Dizer-se que não me sobressaltei seria fazer de mim um homem de pedra que não se move nem se comove, e não se crispa" (MARANHÃO, 1993, p. 11).

Sérgio Afonso Gonçalves Alves, em sua tese Fios da memória, jogo textual e ficcional de Haroldo Maranhão, defende que a duplicação do nome em Haroldo Maranhão implica o jogo de linguagem com a dinâmica da ambiguidade, pois "essa dinâmica se apresenta de forma a repercutir a dubiedade de um nome, a começar pela repetição do nome que serve de título" (ALVES, 2006, p. 130). O autor escreve:

\footnotetext{
A notícia da morte do personagem Miguel aparece duas vezes no obituário do jornal. Varão, amigo e colega de trabalho de Miguel, tem o hábito diário de se ocupar, com prazer, da leitura do obituário, a fim de averiguar nomes, datas, causa mortis e cemitérios. Na opinião de Varão, os “obituários são linhas singelas, não palavras a mais ou a menos". Varão descobre nessa leitura o mesmo prazer proporcionado pela degustação de uma barra de chocolate, minuciosamente preparado por ele, com tempo cronometrado e temperatura
} 
ideal da geladeira para the dar consistência adequada (ALVES, 2006, p. 130131).

O prazer por obituários é peculiar. Isso, para a personagem, tornou-se um ato esporádico, entretanto de valor significativo, porque desse ato emana satisfação nas "leituras de linhas singelas" (MARANHÃO, 1993, p. 11). Dessa forma, se o próprio título abre espaço para o pluralismo, a ruptura com a singeleza alinha-se a uma narrativa veloz, graças à inclinação ao espanto originado pela realidade transvertida em absurdo.

O narrador Varão e Miguel se conheceram quando trabalhavam juntos no escritório de um supermercado. Algum tempo depois da morte de Miguel, dona Miguela, esposa de Miguel, resolve ir morar em Mossoró. Eis o primeiro obituário de Miguel: "Miguel dos Arcanos Folbo Quillet, 61 anos, pancreatite, no hospital de Andaraí. Potiguar, casado com Miguela Pompeu Quillet, tinha dois filhos" (MARANHÃO, 1993, p. 11). Entretanto, quinze anos depois, Varão abre o jornal e encontra na coluna obituária a morte do amigo: "Miguel dos Arcanos Falbo Quillet, 76 anos, de pancreatite, no hospital do Andaraí. Potiguar. Casado com Miguela Pompeu Quillet. Tinha dois filhos e morava em Andaraî" (MARANHÃO, 1993, p. 18).

Como é possível Miguel ter morrido duas vezes? Ao comparar os dois obituários, Varão é atirado à complexa dinâmica da dúvida. A questão de saber se Miguel, tal como foi lido no obituário, está morto ou não, é um desdobramento narrativo como passagem para o enigmático.

\section{A dobra do nome}

A temática do duplo, na cultura ocidental, remete à antiguidade dos mitos gregos e já está presente no mito de Narciso o qual, como resultado da vingança das ninfas que desprezava, apaixona-se pela sua própria imagem refletida na água. A imagem de Narciso, portanto, chega-lhe incompleta e virtual. Nesse aspecto, a morte de Miguel habita o nome dobrado. Assim, o primeiro Miguel é real, o segundo é ilusório. A letra inicial de Miguel é a mesma de Morte. A linguagem carrega o teor semântico da finitude, 
mas elevada à carga de infinito, pois os nomes que se duplicam reverberam no jogo de linguagem. Nesse sentido, Compagnon (1999) escreve:

\footnotetext{
A literatura explora as propriedades referenciais da linguagem; seus atos de linguagem são fictícios, mas, uma vez que entramos na literatura, que nos instalamos nela, o funcionamento dos atos de linguagem fictícios é exatamente o mesmo que o dos atos de linguagem reais, fora da literatura (COMPAGNON, 1999, p. 135).
}

Esses atos de linguagem reais no interior do texto, entretanto, fogem das mãos do leitor quando este se depara com as fugas incoerentes em uma personagem que se confunde com alguém que parece morrer pela segunda vez. Miguel é uno que se faz duplo, ligando-se à traição da lógica. Nesse sentido, na obra, o narrador, sem entender o que está acontecendo, corre para mostrar a notícia à esposa Úrsula, que estranha a notícia da morte de Miguel. Varão recebe um telefonema confirmando o velório e Úrsula recusa-se a acompanhar o marido à cerimônia fúnebre.

A percepção do caráter lúdico no início da narrativa é evidente, assim como a notícia da segunda morte. O inusitado parece ser o símbolo desta novela, ao mesmo tempo em que o fluxo da linguagem insere o leitor em um mundo dobrado:

O telefone tocou. Ela atendeu. E passou-me o auscultador sem uma palavra: “Senhor Varão. É do cemitério de São Francisco Xavier. A família do finado Miguel Quillet avisa que o sepultamento será às 17 horas”.

“Quem está falando?”.

"Meu nome é Cândido. Foi um dos filhos do falecido. Um dos gêmeos. Estão todos muito abalados. Sabem que o senhor foi um grande amigo" (MARANHÃO, 1993, p. 23).

O que parecia ser somente incoerência, agora se torna algo perturbador. A confusão reverbera em Varão, que busca justificar à esposa o que houve. A desordem, entretanto, é intensa: 
Não houve nada? Como não houve nada? Varão, pelo amor de Deus, me diz: não houve nada? Me responde mas me olhando nos olhos: não houve nada?". "Não. Não houve nada. Quero dizer: não se morre duas vezes. Ninguém morre duas vezes. Morre-se uma vez. Todo mundo morre uma vez. E pronto, acabouse. Nós vimos os migueis naquela tarde. Morreu naquele dia. Morreu ou não morreu? Eu vi e você viu (MARANHÃO, 1993, p. 24).

Varão e Úrsula buscam convencer-se de que a morte do amigo já ocorrera. A incredulidade das personagens, primeiramente, é a estratégia para neutralizar o caos gerado pela notícia. Em seguida, ergue-se a dúvida, que conserva o espírito da narrativa sedimentada nas armadilhas da linguagem.

A ficção tem o privilégio de não se prender às amarras da verdade histórica, mas de potencializar as suas próprias verdades, pertencentes ao mundo do texto. A morte é um dos elementos essenciais para a compreensão da dobra do nome. A repetição do eu nas duas mortes é a imagem de um corpo supostamente vivo, pois não se sabe se Miguel morreu ou não: "Morreu ou não morreu? Eu vi e você viu. O Miguel, o Miguel dos Arcanjos Quillet não é. Eu te juro que não é (MARANHÃO, 1993, pp. 24-25). Varão flerta com a ideia de uma possível loucura. Como justificativa à incoerência que o enreda, o narrador elenca uma variedade de loucos, sustentando seu discurso no âmbito comparativo, a fim de construir a possibilidade do redator do obituário também ser um "louco", no sentido cômico do termo:

\footnotetext{
Você acha que a loucura é impossível? A loucura é. Pronto. Os loucos são de várias espécies, Úrsula. De todas as cores. De todos os tamanhos. Uns gritam e outros se calam. Uns querem passar por Jesus, e o primeiro não foi mesmo? [...] Há loucos ótimos, estupendos. A gente pode convidá-los para virem à nossa casa, são quase sempre engraçados, tornam uma noite memorável (MARANHÃO, 1993, p. 21).
}

De maneira implícita, o leitor é induzido a pensar na possibilidade de Varão ser um louco. Entretanto, a oposição entre seriedade e riso se instala na narrativa, como fio construtor de um enredo dúbio, alegorizando a atmosfera indiscernível, zona cinza entre 
verdadeiro e fictício. De todo modo, a linguagem, de aspecto movediço, atinge um ponto profundo, apontando para o onírico, possibilidade esta que chega, por sua vez, para somar nesta narrativa de possibilidades semânticas.

Bachelard (1991), em $O$ direito de sonhar, escreve que o espaço onírico "é feito de essenciais envoltórios, o espaço submetido à geometria e à dinâmica do envolvimento" (BACHELARD, 1991, p. 161). Por se tratar de um lugar envolto de ocultações, a narrativa participa, a fim de exprimir a experiência do hermético, de uma "vontade de ocultação" (BACHELARD, 1991, p. 161). Nesse sentido, Bachelard afirma:

\footnotetext{
Em que espaço vivem nossos sonhos? Qual o dinamismo de nossa vida noturna? O espaço de nosso sonho é verdadeiramente um espaço de repouso? Não possui, antes, um movimento incessante e confuso? Sobre todos esses problemas possuímos pouca luz porque não reencontramos, ao chegar o dia, senão fragmentos de vida noturna (BACHELARD, 1991, p. 159).
}

A imagem de um "movimento incessante" e confuso parece ser elemento fundamental para o trânsito do imaginário, isto é, o dinamismo da experiência do duplo que diretamente provém do diálogo com o estranho. No velório, sem coragem de encarar os presentes, Varão segue a fila dos cumprimentos até abraçar a viúva, que pergunta por Úrsula. Ele responde que ela tinha morrido, o que demonstra, por meio dessa mentira e partindo de uma narrativa em primeira pessoa, ser um narrador não confiável. $\mathrm{O}$ abraço nos gêmeos é frouxo como um abraço de desconhecido, o que faz de Varão, portanto, um estrangeiro para sujeitos que transitavam anteriormente no campo familiar. Ao afastar-se um pouco, começa a mirar a viúva e, para sua surpresa, o rosto é diferente do rosto de Dona Miguela. Ao pedir explicações, pergunta pela Senhora Pompeu:

\footnotetext{
"Senhora: me deve uma explicação. Certamente. Em que ano morreu a Sra. Pompeu?".

“Que???”, ela revelava estranheza.

“A sua mãe? A Sra. Pompeu”.

"Minha mãe? O senhor fala de minha mãe?"

"O seu nome não é Miguela Pompeu Quillet?"
} 


\begin{abstract}
"Miguela? Pompeu? Quillet?"
Os gêmeos tomaram a frente da mãe:

"Quem é o senhor? O que deseja de minha mãe?"

"Fui amigo de seu pai e colega dele no SP."

"SP?", quem indagou foi a Miguela.

"Supermercado do Pericumã. Fomos amicíssimos. E a Dona Miguela sabe muito bem porque foi amiga da Úrsula, minha finada mulher. Seus pais iam à nossa casa todos os domingos para uma macarronada."

Miguela que não era Miguela me encarou como se a um louco. Denunciava temor e amparou-se nos filhos atletas que fechavam o rosto para mim, prontos para saltar e me cravando os dentes no pescoço:

“Jamais na vida vi esse homem. Tirem esse louco daqui." (MARANHÃO, 1993, p. 32).
\end{abstract}

Varão tenta elucidar a dúvida. A experiência de um estranho aniquila a certeza absoluta, uma vez que, após ler o obituário, receber o telefonema, ir ao velório poderiam jogar luz à dúvida, mas, por outro lado, confirmam a confusão: nada parece ser o que é. É por isso que, ao sair do velório, Varão sente-se constrangido. Esse constrangimento é tanto por ter sido expulso quanto por não ter tido a certeza da morte de Miguel. Sobre isso, Alves (2006) escreve:

O conhecimento da morte de Miguel provoca uma avalanche de pensamento e devaneio em Varão. A partir daí a narrativa se desenvolve de forma dúbia, com jogos de palavras, espelhos, repetições de fatos, inclusive com uma segunda publicação da morte de Miguel, muitos anos depois de publicada a primeira e um segundo velório, ao qual Varão também comparece (ALVES, 2006, p. 130131).

É desse desvelamento e velamento operando na trama que esta novela espelha o duplo. A mobilidade do real operado por uma narrativa dúbia em Miguel Miguel fala pela escrita do símbolo, pois o hermetismo da obra é a sua maior joia. Assim, o mundo das representações é o enriquecimento das experiências humanas no mundo do possível. Todo o efeito de incoerência de Varão e Úrsula é resultante da dobra do nome de Miguel. Na primeira morte de Miguel, há a ideia do óbito como finitude humana, ou seja, a repetição 
da morte como condição natural do ser humano. Na segunda, a diferença, abstraída da repetição do nome. Nesse sentido, deslocando as noções de Diferença e repetição de Gilles Deleuze para esta leitura, a primeira morte "tem termos e lugares fixos, enquanto a outra compreende essencialmente o deslocamento e o disfarce" (DELEUZE, 2006, p. 451). A construção de uma oposição entre duas repetições elenca sentidos opostos, que caracterizam a inventividade do que é originado pela dobra do nome. Sobre isso, Deleuze escreve:

\footnotetext{
Uma é repetição de elementos, casos e vezes, por partes extrínsecas; a outra é repetição de totalizantes variáveis internas, graus e níveis. Uma é, de fato, sucessiva, enquanto a outra é, de direito, coexistência. Uma é estática, enquanto a outra é dinâmica. Uma é em extensão, a outra é intensiva. Uma é ordinária, a outra é relevante e repetição de singularidades (DELEUZE, 2006, p. 451).
}

O nome de Miguel torna-se singular quando a repetição se dá no nível da coexistência com a singularidade. Nesse sentido, a duplicação do nome é a forma de variar a palavra que, refletindo no espelho de si própria, passa para o nível do simbólico, para o estado de imagem, ao distanciar-se da originária. Mais precisamente, a repetição do nome Miguel fornece o aparato para o trânsito do metafórico, cuja linguagem demarca as fronteiras de uma lógica que participa do mundo do texto.

\section{A recusa à lógica}

Em Miguel Miguel, Varão, ainda espantado pela incongruência da dupla morte do amigo, contrata um fotógrafo para que registre fotos do velório, a fim de provar visualmente se tudo não passava de delírio e para relatar a Úrsula o absurdo. Ligando à redação do jornal que divulgou o obituário, o jornalista, ao notar o espanto de Varão, ameniza: "Essas coisas às vezes acontecem" (MARANHÃO, 1993, p. 34). Úrsula, por outro lado, não aceita a inversão da lógica, reconhecendo que os dois estão sendo afetados pela notícia das duas mortes: 


\begin{abstract}
"Varão: tu falas com tanta naturalidade, tanta naturalidade, que até parece que quem ficou maluca fui eu".

“E quem é o doido? Eu?".

"Não somos doidos mas estamos ficando. Eu acho, Varão. É simplesmente de enlouquecer. E tu parece que te acostumaste com essa outra morte do Miguel, com a Miguela, com esse enterro maluco. Tu vais a um enterro que é um absurdo, e voltas e me dizes que a Miguela perguntou por mim, que os meninos estão dois homens, que o sepultamento foi às 17 horas e não sei quantos minutos. Não, tudo isso é loucura, não posso admitir, me revolto e me rebelo contra a tua santíssima paciência (MARANHÃO, 1993, p. 35-36).
\end{abstract}

Novamente o senso de incoerência que circunda a obra é trazido na fala de Úrsula. Porém, em um primeiro momento, Úrsula mostra-se extremamente duvidosa e confusa, depois passa a aceitar o absurdo como fato normal, após ver que as fotos do velório mostradas por Varão são da amiga Miguela, de Miguel e dos gêmeos. Varão, em contrapartida, ao notar a serenidade da esposa, demonstra-se irritado.

Paul Ricoeur, em Temps et Récit (Tempo e Narrativa), converte a noção de mimèsis como atividade mimética e o muthus como produção de intriga, significando que a intriga, como operação no interior do texto, enfatiza uma lógica que participa particularmente "no" texto. Utilizando-se da experiência humana no tempo, a narrativa (des)organiza a sua relação com o mundo, para estabelecer a coerência da linguagem literária ou uma espécie de travessia do físico ao metafísico. A composição narrativa, portanto, espelha-se como fingere para criar uma solução poética da realidade, ao compor atos de linguagem que, "relacionados à atividade mimética como compositora de ações, faz o universal surgir" (RICOEUR, 1985, p. 70).

Assim, a ficção de Haroldo Maranhão compõe-se do universal, pois a dubiedade da morte e vida são mistérios ressignificados no plano da palavra. Segundo Antônio Carlos Villaça (1993), Miguel Miguel está sob o domínio da ambiguidade e "vem nos dizer que a realidade é relativa" (MARANHAO, 1993, p. 7). Realidade relativa sob o domínio da ambiguidade veste a complexidade da novela. 
Se até o instante a novela conserva em si mesma a recusa à lógica, o final não é diferente e surpreende ainda mais quanto à noção que a repetição do nome produz. Assim, a surpresa é justamente a representação por excelência de que a linguagem literária se flexiona à complexidade do mundo do possível, construído pela inteligência narrativa presente em Miguel Miguel. Dessa forma, após reviravoltas de absurdos ligados à questão se Miguel está morto ou não, eis que, um dia após o velório, Varão o encontra na rua e o acusa de ter morrido:

\footnotetext{
"Miguel: tu morreste."

"Epa! Como é isso?"

"Morreste, Miguel. Só quero saber quando. Ontem? Ou há quinze anos atrás? E por que diabos me aparece agora no Nápoles? O Obituário publicou ontem o teu nome: pela segunda vez em quinze anos. Eu sou calmo, calmíssimo, tu sabes. Mas a Úrsula está à beira da loucura. Como um irmão, Miguel. Um amigo falando a outro. Eu te peço."

"Varão: eu morri??? Tu sabes que eu morri??? Falas sério ou que brincadeira é essa? É sacanagem, é? Morri? Quando? Onde? De quê? Mas eu tenho vindo trabalhar. Ainda anteontem, pombas, almocei na tua casa! Que novidade já é essa? Tu me deves uma explicação."

"Miguel: eu já fui a dois velórios teus. Dois velórios, Miguel. Ainda ontem o Obituário deu de novo quatro linhas a teu respeito:

MIGUEL DOS ARCANJOS FALBO QUILLET, 76 anos...

“76 anos? Que palhaçada é essa? 76 anos?”, Miguel indignava-se. (MARANHÃO, 1993, p. 43-44).
}

Outra situação inexplicável que compõe o dispositivo ambíguo é o espanto de Miguel, que teria morrido. Ao refutar a ideia de sua morte, Miguel é a metáfora do inexplicável, mas, constituído de palavra a sua morte é signo da imaginação narrativa de Haroldo Maranhão, que dá à dúvida o papel de elemento fundamental na novela. Assim, segundo Bachelard (1989), “A imaginação não é, como sugere a etimologia, a faculdade de formar imagens da realidade; é a faculdade de formar imagens que ultrapassam a realidade, que cantam a realidade" (BACHELARD, 1989, p. 13). 
No ponto de vista sintagmático, Varão narra suas memórias ao articular os verbos no passado: "Dizer-se que não me sobressaltei seria fazer de mim um homem de pedra que não se move nem se comove, e não se crispa" (MARANHÃO, 1993, p. 11). A imaginação, porém, forma imagens que ultrapassam a realidade e desaguam no mundo da linguagem.

Se por um lado Varão poderia simplesmente ter tido espasmos alucinatórios, pois consegue misturar passado e presente, narração em primeira pessoa, dentro do fluxo de memória, por outro, a imaginação em estado de palavra apresenta-se como o fio condutor das possibilidades, cujo descompromisso com a verdade do mundo decepciona a noção de real, ao mesmo tempo em que a linguagem utiliza o real para a realização da narrativa abstrata. Com isso, Haroldo Maranhão devaneia com o leitor, que vai em busca de pistas para desvendar o grande mistério do livro. Miguel morreu uma, duas vezes e no final está vivo? Varão passa a obra tentando desvendar as mortes de seu amigo Miguel. Não obstante, o mistério das verdadeiras ou imaginadas mortes de Miguel permanece suspenso:

\footnotetext{
As duas vezes do Obituário e os dois velórios. Os teus velórios. A Miguela e os meninos que ficaram uns tempos ainda aqui no Andaraí e depois mudaramse para Mossoró. Tudo teria acabado aí. Mas, não. O Obituário de ontem menciona a idade que te mostrei, 76 . $\mathrm{O}$ que faz sentido. $61+15=76$. Isso mesmo. Mas não mudaste nada. Nada. Vejo bem agora. Mudou a Dona Miguela, que nem a reconheci. Reconheceu-a a Úrsula nas fotografias. Os meninos cresceram, dois homões, mais altos e mais fortes que tu. Isso não entendi e não entendo".

Miguel permanece um minuto calado, mirando meus sapatos.

"Agora nem eu, Varão. Minha cabeça dói. e eu sofro com que me dizes. Outro cafezinho, Varão?".

"Não. Obrigado. Muita cafeína faz mal ao pâncreas, Miguel. Estás abusando. Aliás sempre abusaste" (MARANHAO, 1993, p. 46).
}

O leitor, no entanto, não sabe o desfecho desse último encontro, por isso fica sem desvendar o mistério das mortes de Miguel: "Vamos fazer o seguinte. Hoje à noite eu vou 
à tua casa com Miguela e as crianças. Para tirarmos todas essas dúvidas” (MARANHÃO, 1993, p. 46). O onírico e o delírio são possíveis saídas para o esclarecimento do enredo. Entretanto, a novela finaliza em completa ambiguidade. A morte de Miguel é a gênese da narrativa. Se não há uma clareza mais eficaz sobre a morte, é precisamente este mistério que a investigação do passado confronta a ordem estabelecida do discurso. A dobra do nome de "Miguel" para "Miguel Miguel" é um arco a outra temporalidade e desdobra-se a uma conquista discursiva extremamente complexa.

\section{Considerações finais}

O presente artigo desenvolveu um estudo sobre a novela Miguel Miguel, de Haroldo Maranhão e constatou que a dobra do nome de Miguel torna a narrativa complexa, justamente por não haver um desfecho sobre a morte de Miguel, integrando o mundo das possibilidades presentes no discurso literário. Nesse contexto, a literatura, portanto, participa do mundo do possível.

A função da narrativa, escreve Barthes, "não é a de "representar", mas a de constituir um espetáculo que ainda permanece muito enigmático, mas que não poderia ser da ordem mimética" (BARTHES, 1985, p. 45). Nesse sentido, o que está em jogo na obra de Haroldo Maranhão não é simplesmente o elemento referencial, mas o acontecimento da linguagem, "a linguagem inteiramente só, a aventura da linguagem, cuja vinda nunca deixa de ser festejada" (BARTHES, 1985, p. 45). A dobra do nome afronta o regime tradicional da narrativa e promove, consequentemente, a festa da linguagem: eis o que ocorre em Miguel Miguel.

\section{REFERÊNCIAS}

ALVES, S. Fios da memória, Jogo textual e Ficcional de Haroldo Maranhão. Tese (Doutorado) - Faculdade de Letras da Universidade Federal de Minas Gerais, Minas Gerais, 2006. 
BACHELARD, G. O direito de sonhar. Trad. José Américo Motta Pessanha, Jaqueline Raos, Maria Lucia de Carvalho Monteiro e Maria Isabel Raposo. Rio de Janeiro: Bertrand Brasil, 1991.

BACHELARD, G. A poética do espaço. Trad. Antônio de Pádua Danesi. São Paulo, Martin fontes, 1989.

BARTHES, R. Introduction à l'analyse structurale des récits. L'aventure sémiologique. Paris, Ed. du Seuil, 1985.

COMPAGNON, A. O demônio da teoria: literatura e senso comum. Trad. Cleonice Paes Barreto Mourão. Belo Horizonte, Ed. UFMG, 1999.

DELEUZE, G. Diferença e Repetição. Trad. de Luiz Orlandi, Roberto Machado. 2. ed. Rio de Janeiro: Graal, 2006.

MARANHÃO, H. Miguel Miguel. Belém: CEJUP, 1993.

RICOEUR, P. Temps et Récit: Le temps raconté. Paris: Ed. du Seuil, 1985.

VILLAÇA, A. C. Prefácio. In: MARANHÃO, H. Miguel Miguel. Belém: CEJUP, 1993. 